\title{
A REVIEW OF WIRELESS SENSOR NETWORK POTENTIAL IN NIGERIA AS A TOOL FOR SUSTAINABLE DEVELOPMENT
}

\author{
Ajibola Oyedeji, ORCID: 0000-0002-0180-492X \\ Department of Computer Engineering, Olabisi Onabanjo University, Ago-Iwoye, Nigeria \\ ${ }^{*}$ Corresponding author: Ajibola Oyedeji, oyedeji.ajibola@oouagoiwoye.edu.ng
}

Received: 10. 19. 2020

Accepted: 01. 22. 2021

\begin{abstract}
The emerging trend in the world of technology and Information Technology has posed so many opportunities and challenges. Wireless Sensor Network (WSN) is a relatively new and rapidly developing technology due to the advancement and development of the micro-electro-mechanical systems (MEMS) technology. The application areas of wireless sensor and wireless sensor network in the society as tools towards achieving sustainable development range from the health sector through the use of Wireless Body Area Networks (WBANs) to a safer, cleaner and healthier environment. This paper highlights and discusses the potentials of wireless sensor network technology in realizing sustainable development in our society, Nigeria as a case study. WSNs can be employed to improve access to quality health services, increased food production through precision agriculture to a better quality of human resources.
\end{abstract}

Keywords: $\quad$ sensors, WBAN, sustainable development, precision agriculture.

\section{Introduction}

Nigeria has one of the largest stocks of human resources with a population of around 180 million people and in spite of the country's vast resources (human and natural), the majority of the citizens are living below the standard according to UNICEF report of 2018 . Nigeria is ranked low in the world's living standard report as shown in Figure 1 below. It is therefore imperative and essential to study ways to improve the standard of living and there is a great opportunity to achieve this with the advancement in technology. In spite of the vast landmass and human capital available at its disposal, Nigeria's agricultural sector is well short of meeting the demand of the nation thereby resulting in large importation of cash crops as illustrated in Figure 1 [1].

Achieving sustainable development has become a goal in present-day society especially in a developing country with an emerging economy like Nigeria's. The Sustainable Development Goals (SDGs) document is a universal policy framework which consists of various targeted results that include the following:

Zero hunger

Good health and well-being

Clean water and sanitation

Industry, innovation and infrastructure. 


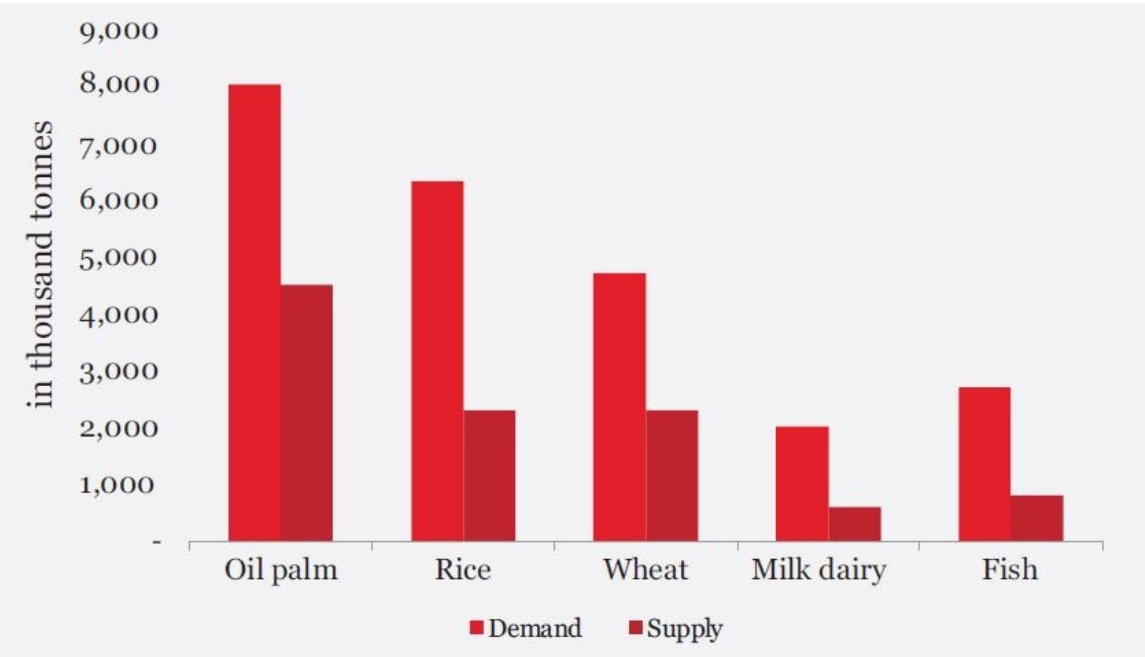

Figure 1. Nigeria's demand and supply gap for key agricultural products (2016) [1].

Information Technology (IT) has been at the forefront of driving development from education to public health, agriculture and environmental management. Wireless Sensor Networks (WSNs) possess capabilities to achieve the improved status of life in the world. In a bid to achieve desired results of the SDGs, this work looks into the potentials of WSNs into fulfilling some of the set goals.

Recent development in micro-electro-mechanical systems (MEMS) technology has been the bedrock for the development of minute low-powered, low-cost and low memory sensor nodes that have small transmission range capabilities [2]. These sensor nodes have capabilities for sensing, processing (such as for data aggregation), data storage and for packet transmission across the network to an external powerful computer for further data analysis and storage. The multi-functionality of the sensor nodes has brought about a rapidly emerging and evolving technology called Wireless Sensor Network [3].

WSN includes a large number of the sensor nodes which have been heavily deployed in the desired area or phenomenon for collecting desired data of interest and transmitting the sensed data to the base station as illustrated in Figure 2.

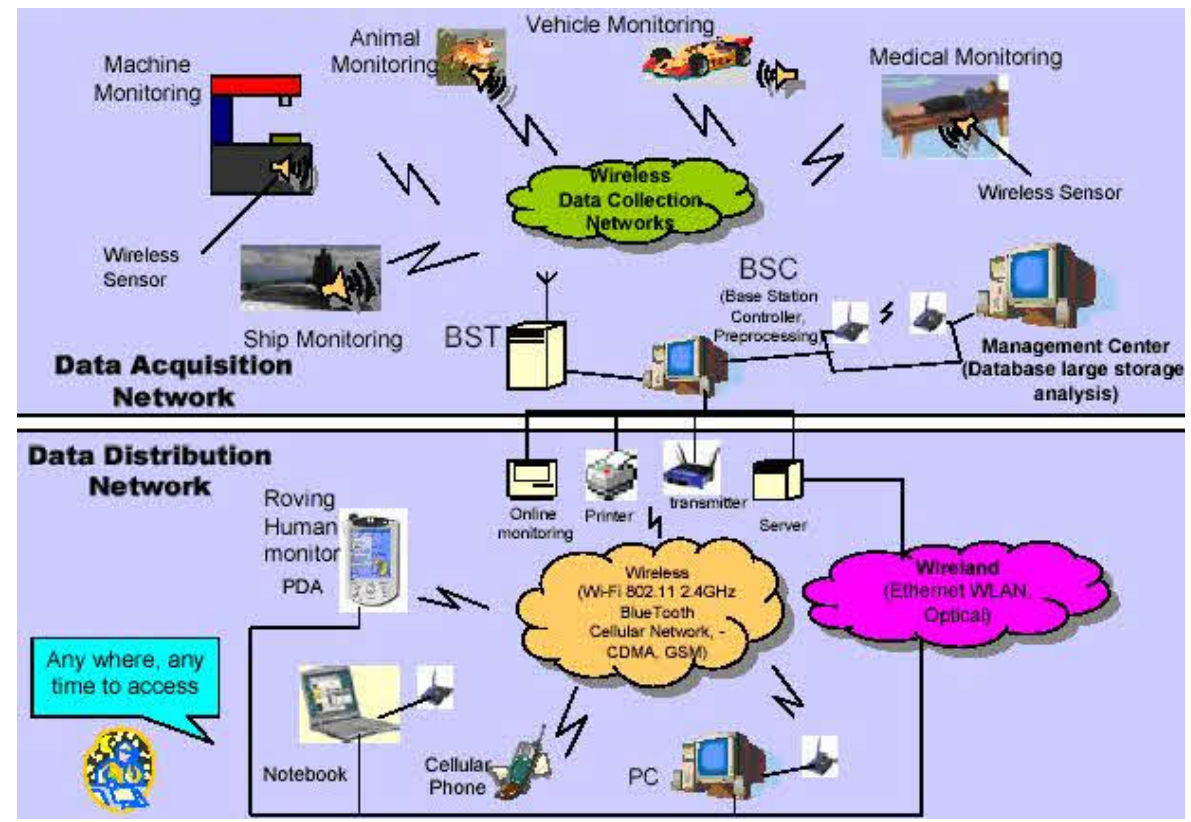

Figure 2. Wireless sensor network. 
WSN is a self-organizing network that can adapt to network topology changes caused by the death of sensor nodes [4]. The most significant advantages of using WSNs, besides low-cost are related to their self-organizing abilities and versatility of sensors. They are deployed for different applications ranging from weather, industrial process and environmental monitoring to military applications, public health and agriculture [5, 6]. A sensor generally always consists of a transceiver (transmitter and receiver), a processor for basic data aggregation, low-memory unit, and power unit, with optional units such as GPS, mobility.

With Nigeria declared as a developing nation and its technology fast-growing, it is therefore very important and useful to study the state of the WSN technology in Nigeria and its various uncharted potentials. This paper aims to study the various potentials of WSN and ways to apply them to achieve sustainable development in Nigeria.

\section{Wireless Sensor Network Potentials in Nigeria}

WSNs have capabilities for observing and measuring various physical phenomena in the environment. WSNs can be utilized in Nigeria in diverse areas to improve access to health care, improving food production and processing, the security of life and properties. WSNs are capable of measuring diverse phenomena such as contaminant levels in the water, pollutants in the air, and the flow of water for irrigation. Figure 3 illustrates the various application areas of WSN varying from health care to agriculture, transportation, environmental monitoring and security or surveillance. A wearable WSN for indoor environmental monitoring to measure and monitor the concentration of $\mathrm{CO}_{2}$ was designed in [2].

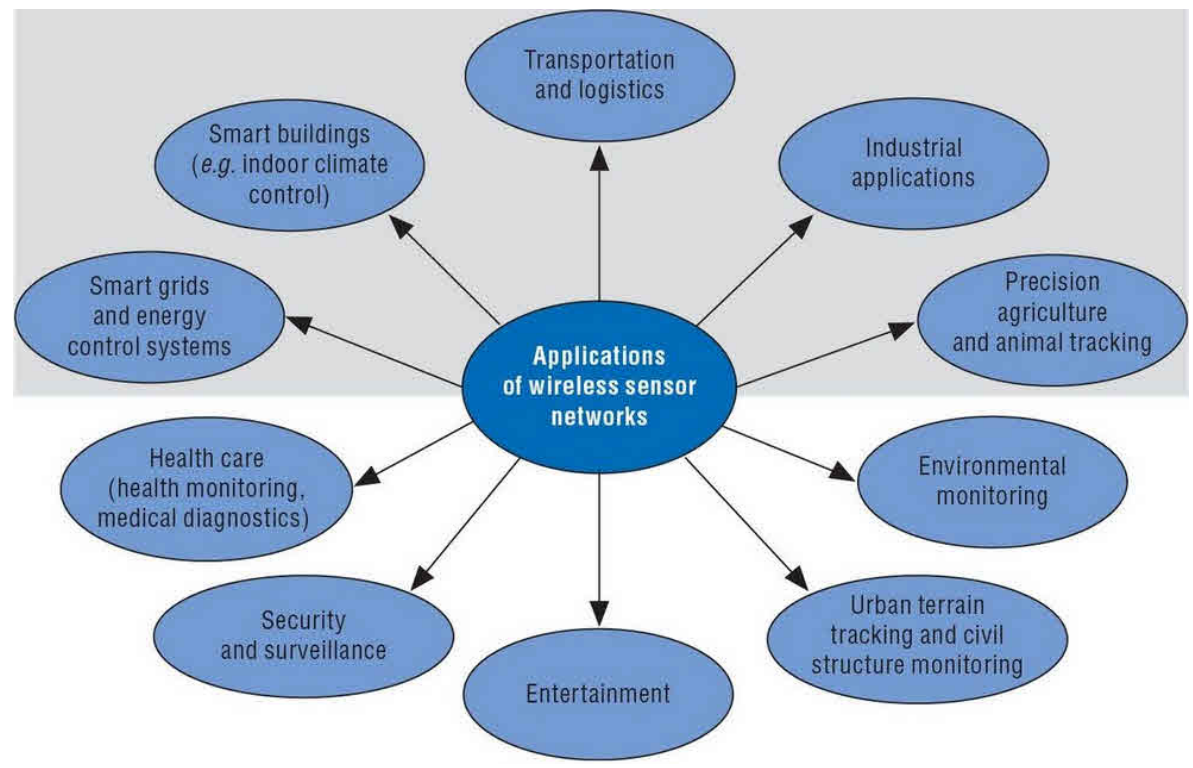

Figure 3. Applications of wireless sensor network.

\section{Health Care}

The health sector is one of the vital sectors to be considered in a developing economy. The health sector in any economy forms the backbone of its growth and development. Nigeria's health sector is epileptic one of the poorest in the world with Nigeria ranked 187 out of 191 countries in world health systems as reported according to the World Health Organization's analysis result of the world's health system in 2017. Factors affecting the overall Nigerian health system performance include: inadequate 
health facilities and structures, poor management of human resources, poor motivation and remuneration, inequitable and unsustainable health care financing, skewed economic and political relations, corruption, illiteracy, decreased government spending on health, high user fees, absence of integrated system for disease prevention, surveillance and treatment, inadequate access to healthcare, shortage of essential drugs and supplies and inadequate health care providers [7].

In the health care sector, wireless sensor networks have various application potentials in Nigeria ranging from bedside monitoring to medical diagnostics that can be used to effectively improve the health care delivery. Application of wireless sensor networks in the health sector has made provision of medical services more efficient which in turn has contributed to the development of the countries of use. There is a dire shortage of health workers in Nigeria as a result of economic and social brain drain and has been estimated that the physician to patient ratio stands at about $27: 100,000$ is very low in Nigeria and this can be augmented with the use of WSNs which can help reduce the pressure on medical practitioners [8]. WSN can be applied in the health sector for remote monitoring and telemedicine which will, in turn, reduce the pressure and demand on the limited facilities and physicians available.

Health Monitoring: WSNs are used to monitor patients in hospitals or at home. The WSNs sensors are used to measure, monitor and record the patient's data such as blood pressure, heart rate, temperature and other vital data. The application of WSNs for patient monitoring offers some advantages over the wired systems like the ease of use, reduced risk of infections, reduced risk of failures, enhanced mobility and lower the cost of delivery [9].

From Figure 4 above, the wireless sensors acquire data from the patient ranging from the heartbeat to the blood pressure and necessary data, this data is then transmitted to the medical server of the hospital where the physician accesses it, assesses and prescribes necessary treatments and monitor how the patient is responding to the treatment administered.

Wireless Body Area Networks (WBAN): This is the design of wearable devices using wireless sensors which are wirelessly connected. The WBAN is also used to monitor patients, that is, it is capable of alerting the doctor of any irregularities about the patients like heart attack, high blood pressure and so on. It also helps people by providing healthcare services such as memory enhancement, medical data access, cancer detection, asthma detection, and monitoring blood glucose [4].

Telemedicine: With the Nigeria population, with a reasonable percentage of this population living in remote rural areas where

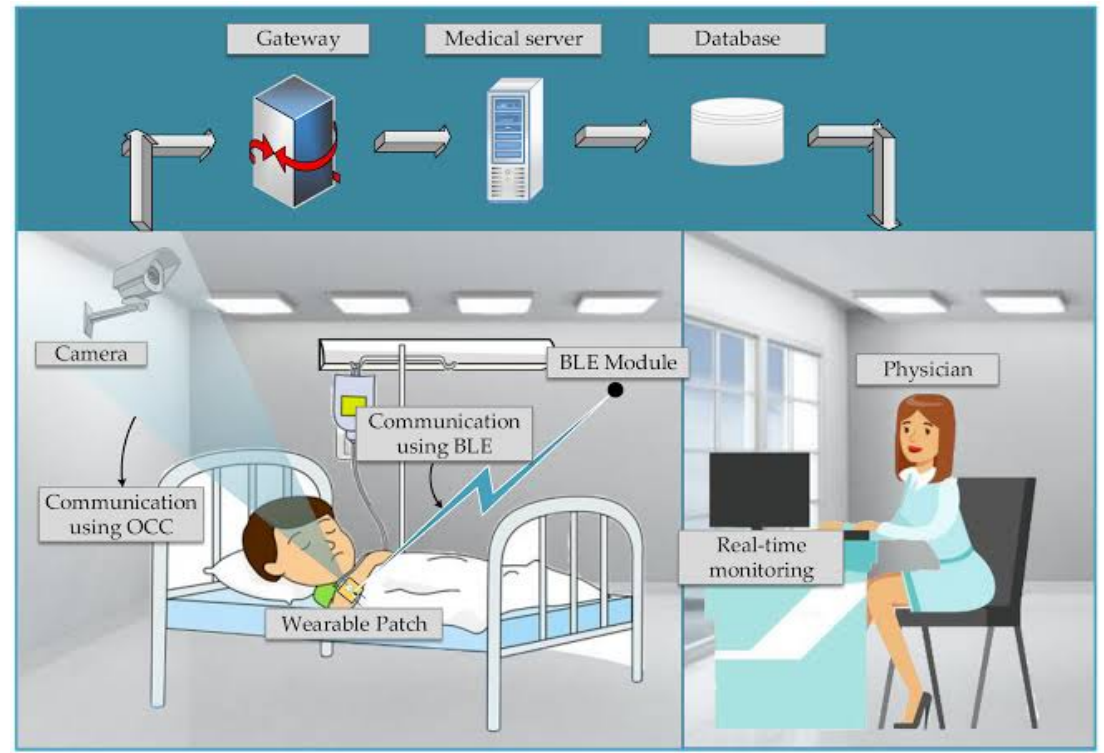

Figure 4. Patient monitoring system using WSN. 
there is little or no access to basic health care facilities, telemedicine has been proposed as another way of improving the health sector and quality health care delivery. Telemedicine is defined as the delivery of health care and the sharing of medical knowledge over a long distance using telecommunication means [3]. This helps in providing quality health care delivery and education to remote areas and also helps lower the cost of health care which in turn enables sustainable development. A typical telemedicine system is shown in Figure 5 below.

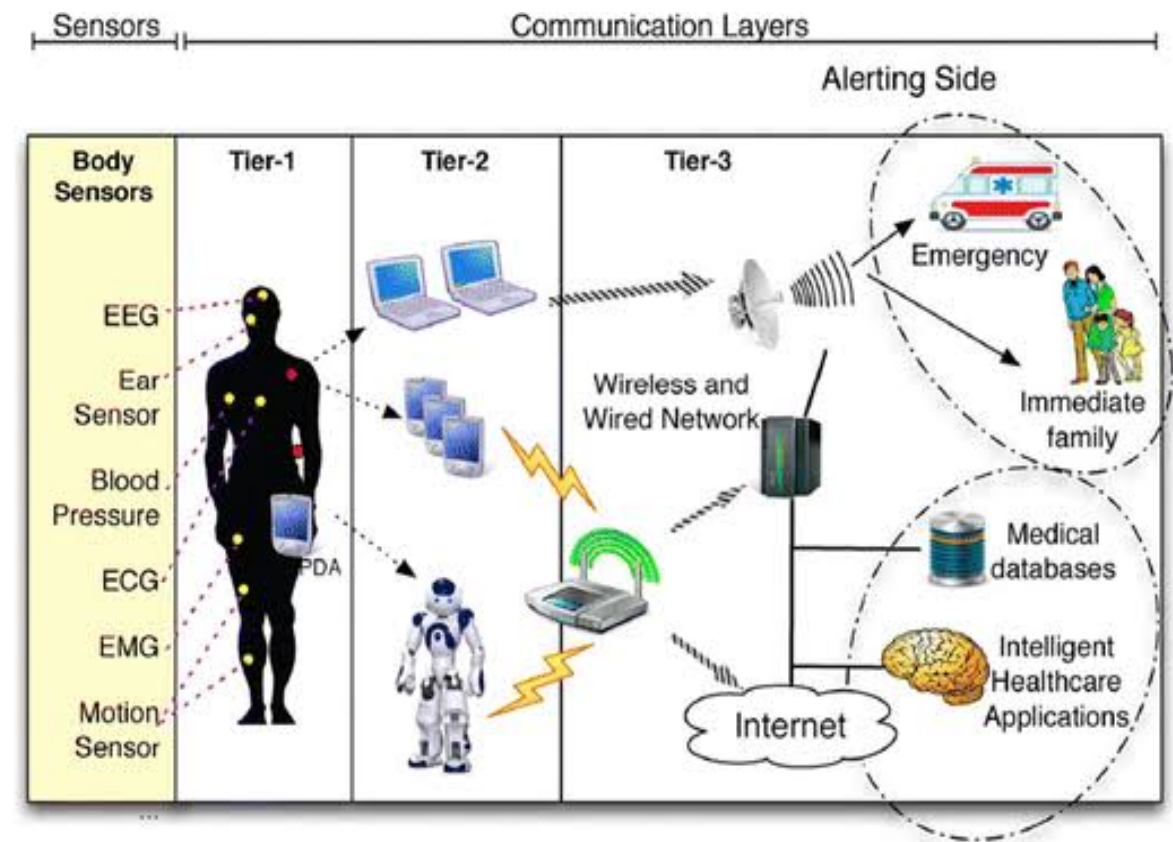

Figure 5. Telemedicine system utilizing WSN.

\section{Agriculture}

With the country faced with the challenges of the falling oil price and the need for diversification, agriculture is a viable alternative to oil. This is because the agricultural sector used to be the major source of revenue to the country through the export of agricultural produce like cocoa before the discovery of oil, even at that, the agricultural sector is said to contribute about $40 \%$ to the country's GDP despite its low productivity. Therefore to improve the low productivity in the agricultural sector, modern technologies need to be adopted. Modern technologies like precision farming using WSN has been identified as one of the ways out [10].

Wireless sensor networks have various applications in the agricultural sector, some of which include animal tracking and monitoring system, monitoring the soil condition at different times. With the growing population of the world which has led to an increase in the demand for food and other agricultural produce. To meet the unending demand, various techniques have been proposed to make cultivation and other agricultural practices easier. Some of the techniques proposed are precision agriculture, remote sensor, fire detection, etc. These techniques make use of a wireless sensor network to improve productivity for sustainable development.

Precision Agriculture (PA) is a production system that promotes variable management practices within a field, according to site conditions.

This system is based on new tools and sources of information provided by modern technologies. 
These include the global positioning system (GPS), geographic information systems (GIS), yield monitoring devices, soil, plant and pest sensors, remote sensing, and variablerate technologies for applicators of inputs. Precision agriculture is one of the top ten revolutions in agriculture. Precision agriculture enables farmers to be able to monitor the soil temperature, humidity, etc. and the farmers are provided with an application which can be used to activate different functions like irrigating (drip irrigation) when the soil is dry and others. Precision agriculture is the future of agriculture because of the ease of use [11].

The precision agriculture cycle consists of the following stages as illustrated in Figure 6; measurement of withinfield spatially variable soil and crop parameters and monitoring of local weather conditions (data collection), mapping of within-field soil and crop parameters (data collection), mapping of spatially variable rate crop input applications (interpretation), spatially

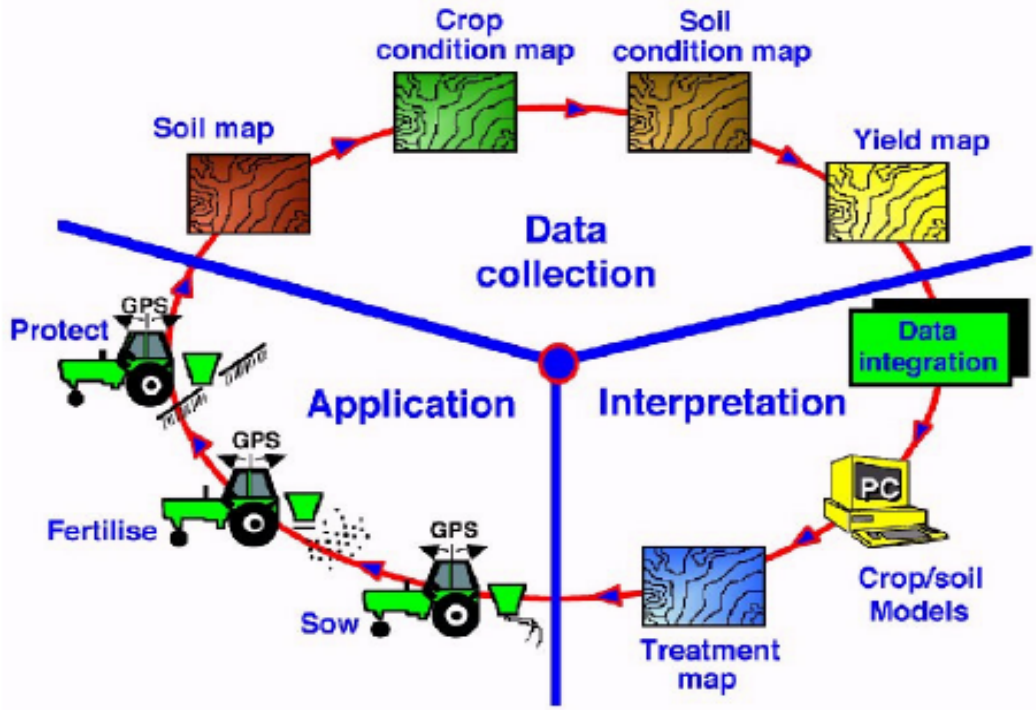

Figure 6. Precision agriculture cycle. variable rate crop input applications (application).

The use of precision agricultural practices has resulted in reduced cost of recurrent expenditure as it optimizes the resources been used. There is a considerable ongoing effort in collecting remote sensing data at multiple times to conduct near real-time soil, crop and pest management. PA uses the various measurements gathered to optimize the amount of fertilizer, water, soil nutrients and pesticides and herbicides to be utilized thereby removing their under-application or over-application [12].

\section{Water Quality Monitoring}

Water is very important to creatures as healthy and clean water is important to man sustaining life because of its numerous applications from cooking, drinking to personal hygiene, etc. Water is also needed in agriculture and industries. The importance of water to man cannot be overemphasized, that is why the provision of clean and healthy water for the populace is of great importance. The statistics of water-borne diseases in Nigeria is worrisome because of the inadequate supply of quality water while some of her citizens who live in remote areas don't even have access to the quality water supply at all. This is as a result of dilapidated water infrastructures and negligence on the side of the government in monitoring the quality of water sold in the country.

As an example of a potential application, consider the incessant incidents of contamination spilling into different rivers in Nigeria, which serve as the main source of drinking water for many people especially in the rural areas. Determining the rate of flow and sometimes the direction of the river requires coordination of multiple sampling points. Sensors periodically taking samples at multiple locations along the river could determine the rate, quantity, and direction of contaminant flow as shown in Figure 7. 


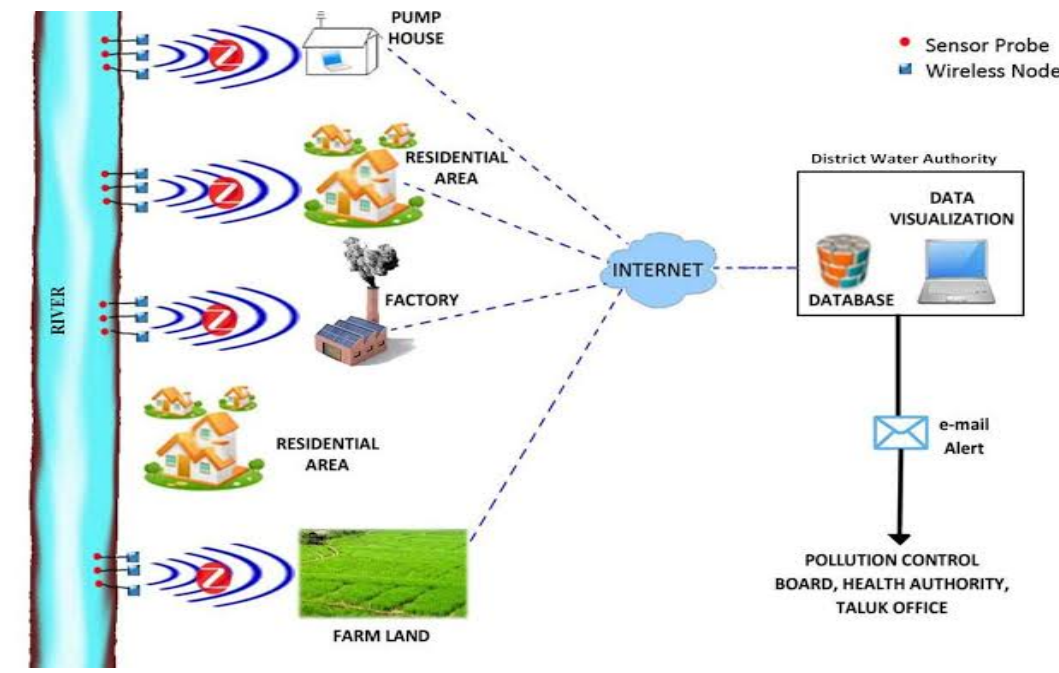

Figure 7. A typical smart water monitoring system using WSNs

WSNs can be applied in monitoring the quality of water distributed in the country after setting a standard. The parameters that can be monitored include;

1. The $\mathrm{pH}$ level is the measure of the degree of acidity or alkalinity of the water distribution. However, a pH level between 6.0 and 9.0 is recommended for distribution systems.

2. Electrical conductivity: this is the measure of compatibility to pass an electric current. Conductivity is used as an indication of the concentration of conductive ions that normally come from dissolved salts and other inorganic material. The more the dissolved salts present, the higher the conductivity. Drinking water should have a conductivity that ranges between 0 and $2500 \mathrm{~S} / \mathrm{cm}$.

3. Oxidation-Reduction Potential (ORP): this a measure of how strongly electrons are transferred between component species in a solution. This indicates the ability of water to get rid of its contaminants. A healthy should have a high ORP [13].

4. Turbidity: this indicates the concentration of suspended and colloidal material in water and it is measured in Nephelometric Turbidity Units (NTU). Drinking water should have turbidity that is less than 1 NTU [13].

\section{Challenges and Proposed Solutions}

A lot of factors have affected the implementation and integration of wireless sensor networks in Nigeria towards achieving sustainable development. The first major challenge is the lack of will-power by the government of Nigeria towards technological development. Politics and poor governance in Nigeria as evident in the mismanagement of public resources allocated to the different sectors and poor technical ability of personnel's placed in charge of the ministries. The second major challenge is the limited information or limited awareness of people to the various potentials and advantages achievable through the utilization of WSNs in Nigeria.

Nigeria has about 54 federal tertiary teaching hospitals but are all in dire need of facility and equipment upgrade. For Nigeria to solve the health challenges especially with the dearth of medical personnel, all the tertiary teaching hospitals should be upgraded and equipped with state of the art telemedicine facilities. The users of these facilities located in the cities who majorly have access to working internet facilities can make use of these WSN facilities for health monitoring and reporting. 
The use of technology in agricultural monitoring should be encouraged to increase yield and reduce the overhead cost of applying fertilizers and irrigation systems. The Federal Ministry of agriculture should set up large agricultural estates across the 36 states of the federation. These estates should be equipped with sensors for precision agriculture to measure the soil moisture and with the application of drip irrigation will optimize the moisture need of the individual plants resulting in reduced water wastage especially in arid zones.

To achieve the nation's quest to supply its citizens with clean and potable water, the water corporations across the various states of the federation should be equipped with facilities for remote monitoring of the quality of water delivered to its various subscribers. Data centers should be set up across the states to remotely monitor, analyze, process and store data and information gotten to better serve the millions of customers depending on the corporations for usable water.

\section{Conclusion}

This study reviews the potentials of Wireless Sensor Networks in achieving sustainable development in a developing country like Nigeria. WSNs can be designed, developed and integrated into critical areas such as the health sector, agricultural sector and in environmental health monitoring to improve the way of life of the citizens of Nigeria.

It is highly recommended that more attention to be given to the implementation of WSN technology in the area of health, agriculture and environmental monitoring especially with the advent of the Internet of Things (loT). With the right policies and a working framework for the implementation and deployment of WSN, Nigeria can improve its citizens' standard of living and take a giant step towards achieving the Sustainable Development Goals.

\section{References}

1. Pwc Report. Transforming Nigeria's Agricultural Value Chain. 2017.

2. Antolin D, Medrano N, Calvo B, Perez F. A Wearable Wireless Sensor Network for Indoor Smart Environment Monitoring in Safety Applications. Sensors. 2017;17:365-78.

3. Salamah M, Oyedeji AO. Regional-Based LEACH For Energy Efficiency In WSNs. International Research Journal of Electronics and Computer Engineering. 2016;2:7-13.

4. Cao H, Leung V, Chow C, Chan H. Enabling technologies for wireless body area networks: A survey and outlook. IEEE Communications Magazine 2009;47:84-93.

5. Aponte-Luis J, Gomez-Galan JA, Gomez-Bravo F, Sanchez-Raya M, Alcina-Espigado J, Teixido-Rovira PM. An Efficient Wireless Sensor Network for Industrial Monitoring and Control. Sensors. 2018;18:182-96.

6. Milenkovic A, Otto C, Jovanov E. Wireless sensor networks for personal health monitoring: Issues and an implementation. Computer Communications. 2006;29:2521-33.

7. Emmanuel AN. Challenges of implementing sustainable health care delivery in Nigeria under environmental uncertainty. Journal of Hospital Administration. 2016;3:113-26.

8. Muhammad F, Abdulkareem JH, Chowdhury AA. Major Public Health Problems in Nigeria: A review. South East Asia Journal of Public Health. 2017;7:6-11.

[9. Sadiku MNO, Eze KG, Musa SM. Wireless Sensor Networks for Healthcare. Journal of Scientific and Engineering Research. 2018;5:210-13.

10. Adebayo S, Akinwunmi AO, Aworinde HO, Ogunti EO. Increasing Agricultural Productivity in Nigeria Using Wireless Sensor Network (WSN). African Journal of Computing and ICT. 2015;8:121-28.

11. Seelan SK, Laguette S, Casady GM, Seielstad GA. Remote sensing applications for precision agriculture: A learning community approach. Remote Sensing of Environment. 2003;88:157-69.

12. Mulla DJ. Twenty five years of remote sensing in precision agriculture: Key advances and remaining knowledge gaps. Biosystems Engineering. 2013;114:358-71.

13. Pule M, Yahya A, Chuma J. Wireless sensor networks: A survey on monitoring water quality. Journal of Applied Research and Technology. 2017;15:562-70. 